\title{
Produção de alface hidropônico em diferentes condutividades elétricas
}

\section{Hydroponic lettuce yield in differents electrical conductivity}

\author{
Regiane Cristine Filgueiras ${ }^{1}$; Hideaki Wilson Takahashi ${ }^{2 *}$; \\ Elisabete Rumiko Yonamini Beninni ${ }^{3}$
}

\begin{abstract}
Resumo
Em cultivos hidropônicos é usual avaliar o teor de nutrientes da solução nutritiva através da condutividade elétrica. Este trabalho teve como objetivo determinar a melhor condutividade elétrica da solução nutritiva para o cultivo de alface tipo crespa cultivar Verônica. Testaram-se 4 tratamentos que consistiram em diferentes condutividades elétricas da solução nutritiva. A solução nutritiva de Hoagland \& Arnon (1950) foi utilizada como padrão, da qual realizou-se várias diluições até a obtenção de quantidades ideais de cada nutriente para atingir as diferentes condutividades elétricas: 1,$0 ; 1,5 ; 2,0 ; \mathrm{e} 3,0 \mathrm{mS} \mathrm{cm}^{-1}$. $\mathrm{O}$ delineamento estatístico utilizado foi blocos, com quatro tratamentos e seis repetições. A partir dos resultados obtidos pôde-se concluir que o tratamento $\mathrm{CE}=1,0 \mathrm{mS} \mathrm{cm}{ }^{-1}$ proporcionou boa produção, com concentrações adequadas de $\mathrm{N}, \mathrm{P}, \mathrm{K}, \mathrm{Ca}, \mathrm{Mg}, \mathrm{S}$ e baixo teor de nitrato, estando abaixo do limite máximo de nitrato permitido para alface, na Europa.
\end{abstract}

Palavras-chave: Lactuca sativa L.; solução nutritiva; nutrientes; nitrato.

\begin{abstract}
In hydroponic culture is common to evaluate the concentration of nutrient solution through electrical conductivity (EC). The aim of this work was to evaluate the best electrical conductivity of nutrient solution to lettuce crop, cv. Verônica. Four treatments were studied in differents electrical conductivity of nutrient solution. The Hoagland \& Arnon (1950) nutrient solution was used as pattern, which to make several dilution until to get ideal quantities of each nutrient to reach the differents electrical conductivity: 1,$0 ; 1,5 ; 2,0 ; 3,0 \mathrm{mS} \mathrm{cm}{ }^{-1}$. The statistic design were blocks, with four treatments and six replications. In the treatment $\mathrm{EC}=1,0 \mathrm{mS} \mathrm{cm}{ }^{-1}$ was obtained good yield, with apropriate concentration of $\mathrm{N}, \mathrm{P}, \mathrm{K}, \mathrm{Ca}, \mathrm{Mg}$ and $\mathrm{S}$ and low level of nitrate, lower than the maximum allowed by the Comission of the European Communities.
\end{abstract}

Key words: Lactuca sativa L.; nutrient solution; nitrate.

\footnotetext{
1 Enga ${ }^{\text {a }}$ Agra ${ }^{a}$. Departamento de Agronomia, Universidade Estadual de Londrina, C.P. 6001, CEP 86.051-990, Londrina, PR. E-mail: beninni@sercomtel.com.br.

2 Eng $^{\text {o. }}$ Agr ${ }^{\circ}$. Dr. Professor do Departamento de Agronomia, Universidade Estadual de Londrina, C.P. 6001, CEP 86.051-990, Londrina, PR.

3 Eng $^{\mathrm{a}}$. Agr . MS.

* Autor para correspondência.
} 


\section{Introdução}

A hidroponia é uma técnica alternativa de cultivo que está se desenvolvendo rapidamente como meio de produção vegetal, principalmente em hortaliças de cultivo protegido. Consiste na substituição do solo por uma solução aquosa, que contém os elementos minerais essenciais ao desenvolvimento dos vegetais (GRAVES, 1983).

Para cultivos hidropônicos é usual avaliar o teor de nutrientes na solução nutritiva de forma indireta, medindo sua condutividade elétrica (VERDONCK; VLEESCHAUWER; BOODT, 1981). Segundo Bliska e Honório (1996), a avaliação da condutividade elétrica tem sido recomendada para a reposição de nutrientes na solução nutritiva, mas não identifica a faixa crítica de nutrientes e nem quais estão em falta ou em excesso.

Como a solução é composta em grande parte por elementos metálicos, o nível estimado da concentração desses nutrientes pode ser obtido medindo-se a capacidade da solução nutritiva de conduzir corrente elétrica, ou seja, quanto maior a concentração de substâncias, maior será a capacidade da solução nutritiva de conduzir corrente elétrica (STAFF, 1998).

A CE é proporcional ao conteúdo total de íons, assim uma queda na CE é acompanhada por uma queda proporcional na quantidade total de íons disponíveis para absorção por parte das raízes. No entanto, sais diferentes apresentam CEs diferentes, portanto, para cada formulação haverá uma função linear relacionando CE e quantidade total de íons dissolvidos (MARTINEZ, 1997).

Os valores de condutividade elétrica são proporcionais à concentração de vários íons em solução, e da mesma forma ao seu potencial osmótico (COSTA et al., 2001). De acordo com Bresler e Hoffman (1986 apud COSTA et al., 2001), a absorção de água pelas plantas, através do sistema radicular, é influenciada pelo potencial osmótico do meio nutritivo. Huett (1994), afirma que a condutividade da solução nutritiva não influencia somente a absorção de água, mas também a absorção de nutrientes, estando ambas intimamente ligadas.

Segundo Beltrão et al. (1997 apud COSTA et al., 2001), as mudanças na absorção de água e nutrientes, proporcionadas pela variação da condutividade do meio nutritivo, levam a alterações da fisiologia das plantas. Essas alterações relacionam-se, dentre outros fatores, à abertura estomática e ao aumento ou diminuição da área foliar, estando esses fatores intimamente ligados com a eficiência fotossintética, e consequentemente, com a produção de material seco pelas plantas (COSTA et al., 2001).

A troca da solução nutritiva impede o acúmulo de certos nutrientes não absorvidos na mesma proporção que os demais, que poderiam interagir negativamente na absorção ou causar toxidez. O problema é mais sério para os micronutrientes, onde o limite entre carência e toxidez muitas vezes é estreito (MARTINEZ, 1997).

Durante a absorção de nutrientes pelas plantas de alface cultivadas hidroponicamente, ocorre uma diminuição na concentração de todos os elementos da solução nutritiva, refletindo portanto diretamente na CE. Existe muita controvérsia com relação ao melhor valor de condutividade elétrica a ser adotado para o cultivo da alface em hidroponia. Acreditase também que esses valores devem variar de acordo com a cultivar adotada, bem como as condições climáticas (COSTA et al., 2001).

O objetivo deste trabalho foi determinar a melhor condutividade elétrica da solução nutritiva, para o cultivo hidropônico de alface crespa cultivar Verônica.

\section{Material e Métodos}

O experimento foi realizado em sistema hidropônico, através da técnica NFT (fluxo laminar de nutrientes) em ambiente protegido, no Centro de Ciências Agrárias da Universidade Estadual de Londrina (UEL); latitude, $23^{\circ} 23 \mathrm{~S}$; longitude , $51^{\circ} 11^{\circ} \mathrm{W}$ e altitude de $566 \mathrm{~m}$. 
Foram utilizadas sementes de alface tipo crespa, cultivar Verônica. A semeadura foi realizada em bandejas de poliestireno expandido, utilizando como substrato uma mistura de vermiculita + húmus. Quando as plântulas apresentaram de 08 a $10 \mathrm{~cm}$ ou de 3 a 4 folhas verdadeiras, foram lavadas para retirada do substrato e transplantadas para as bancadas hidropônicas. O transplante ocorreu em 13 de julho e a colheita em 21 de agosto de 2001.

Cada bancada possuía três canaletas de PVC com 2,0 $\mathrm{m}$ de comprimento e 3 polegadas de diâmetro. $\mathrm{O}$ espaçamento entre plantas foi de $20 \mathrm{~cm}$, totalizando 20 plantas por bancada. As bancadas possuíam 1,5\% de declividade para permitir que a solução nutritiva retornasse ao reservatório por gravidade. Cada reservatório possuía capacidade para 20 litros de solução nutritiva. A circulação da solução foi obtida mediante recalque com uma bomba de $32 \mathrm{~W}$, ligada a um temporizador, que a mantinha 20 minutos ligada e 10 minutos desligada durante o dia e 10 minutos ligada e 40 minutos desligada durante à noite. Para a realização do experimentou utilizou-se quatro bancadas hidropônicas, uma para cada condutividade elétrica estudada.

A solução nutritiva de Hoagland e Arnon (1950) foi utilizada como padrão, da qual realizou-se várias diluições até a obtenção de quantidades ideais de cada nutriente para atingir as diferentes condutividades elétricas analisadas.

Diariamente os reservatórios foram completados com água até 20 litros. Após a homogeneização da solução nutritiva, coletava-se amostras para monitoramento da condutividade elétrica $(\mathrm{CE})$ e $\mathrm{pH}$. $\mathrm{O} \mathrm{pH}$ foi mantido numa faixa entre 5,8 e 6,2 adicionando-se $\mathrm{HNO}_{3} 0,1 \mathrm{~N}$ ou $\mathrm{KOH}$ $0,1 \mathrm{~N}$ e quando a $\mathrm{CE}$ diminuía $25 \%$ da inicial, a solução nutritiva era trocada.

Após a colheita, as plantas foram separadas em raiz e parte aérea, pesadas e lavadas em águas corrente, destilada e deionizada. As amostras foram colocadas para secar em estufa com circulação de ar à $60^{\circ} \mathrm{C}$ para obtenção de peso seco. Após secas, as amostras foram moídas e condicionadas em frascos fechados para realização das análises químicas.

Para a análise química dos nutrientes utilizou-se somente a parte aérea das plantas. Realizou-se a digestão nítrico-perclórica para determinação de $\mathrm{P}, \mathrm{K}$, $\mathrm{Ca}, \mathrm{Mg}$ e S. Através do extrato obtido nessa digestão, determinou-se cálcio e magnésio por Absorção Atômica, fósforo por Colorímetro, potássio por Fotômetro de Chama e enxofre por Turbidimetria de Sulfato de Bário. Para determinação de N, realizou-se digestão sulfúrica e destilação em Micro Kjeldahl e para análise de nitrato utilizou-se a metodologia descrita por Cataldo et al. (1975).

O delineamento estatístico utilizado foi blocos com quatro tratamentos e seis repetições. Os tratamentos corresponderam a diferentes valores de condutividade elétrica da solução nutritiva: $\mathrm{CE}_{1}=1,0$; $\mathrm{CE}_{2}=1,5 ; \mathrm{CE}_{3}=2,0 ; \mathrm{CE}_{4}=3,0 \mathrm{mS} \mathrm{cm}{ }^{-1}$. Para comparação de médias utilizou-se Teste de Tukey à $5 \%$ de probabilidade.

\section{Resultados e Discussão}

Através dos resultados de matéria fresca e seca da parte aérea e matéria fresca das raízes das plantas de alface, observa-se uma tendência no aumento dos pesos conforme ocorre o aumento da condutividade elétrica da solução nutritiva até o tratamento $\mathrm{CE}_{3}=$ $2,0 \mathrm{mS} \mathrm{cm}^{-1}$, porém, em nenhum dos resultados observou-se diferença significativa entre os tratamentos analisados (Tabela 1) Já no tratamento $\mathrm{CE}_{4}=3,0$ $\mathrm{mS} \mathrm{cm}{ }^{-1}$ os valores diminuem, sendo superiores somente aos obtidos no tratamento $\mathrm{CE}_{1}=1,0 \mathrm{mS} \mathrm{cm}^{-1}$ ). Isso demonstra que as soluções nutritivas com as diferentes condutividades elétricas não influenciaram o desenvolvimento das plantas. Este fato pode ser atribuído à proporção de 1 litro de solução nutritiva por planta, que permitiu uma concentração de nutrientes sem que houvesse prejuízos na produtividade ou a faixa de CE estudada não foi suficiente para demonstrar resultados significativos. No experimento realizado por Costa et al. (2001) a menor produção de massa seca $\left(8,12 \mathrm{~g} \mathrm{pl}^{-1}\right)$ deu-se em fun- 
ção da maior condutividade elétrica estudada $(4,21$ $\mathrm{mS} \mathrm{cm}{ }^{-1}$ ), concordando com os resultados obtidos por Beltrão et al. (1997 apud COSTA et al., 2001) em que aumentos na condutividade elétrica levaram a diminuição da produção de material seco, bem como da produtividade.

Tabela 1 - Matéria fresca e seca (g) de alface, cv. Verônica, em função das diferentes condutividades elétricas da solução nutritiva.

\begin{tabular}{cccccc}
\hline $\mathbf{C E}$ & \multicolumn{2}{c}{ Matéria Fresca $(\mathbf{g})$} & & \multicolumn{2}{c}{ Matéria Seca $(\mathbf{g})$} \\
\cline { 2 - 3 } \cline { 5 - 6 }$\left(\mathbf{m S ~ c m}^{-\mathbf{1}}\right)$ & Parte Aérea & Raiz & & Parte Aérea & Raiz \\
\hline 1,0 & $238,64 \mathrm{a}^{(*)}$ & $34,01 \mathrm{a}$ & & $12,21 \mathrm{a}$ & $2,19 \mathrm{a}$ \\
1,5 & $316,34 \mathrm{a}$ & $35,33 \mathrm{a}$ & & $13,63 \mathrm{a}$ & $1,76 \mathrm{a}$ \\
2,0 & $306,69 \mathrm{a}$ & $41,03 \mathrm{a}$ & & $14,78 \mathrm{a}$ & $2,23 \mathrm{a}$ \\
3,0 & $258,01 \mathrm{a}$ & $38,96 \mathrm{a}$ & & $12,81^{\mathrm{a}}$ & $2,24 \mathrm{a}$ \\
\hline
\end{tabular}

* Médias seguidas de mesma letras na coluna não diferem entre si ao nível de 5\% de probabilidade, pelo Teste de Tukey.

A análise das concentrações de nitrogênio, fósforo, potássio, cálcio, magnésio e enxofre na parte aérea das plantas de alface demonstra que todos os nutrientes estavam dentro das faixas de concentrações adequadas de macronutrientes para a cultura da alface, estabelecido por Raij (1996), mesmo na menor condutividade elétrica estudada (Tabela 2). Koefender (1996) avaliando o desenvolvimento das plantas de alface, cv. Verônica, em a diferentes manejos da solução nutritiva obteve concentrações $\mathrm{N}$, $\mathrm{P}, \mathrm{K}, \mathrm{Ca}, \mathrm{Mg}$ e $\mathrm{S}$ entre: $\mathrm{N}=36,36$ e 43,46; $\mathrm{P}=7,33$ e 9,52; $\mathrm{K}=61,97$ e 71,$14 ; \mathrm{Ca}=9,34$ e 10,$02 ; \mathrm{Mg}=2,11$ e 2,67; $\mathrm{S}=2,27$ e $2,37 \mathrm{~g} \mathrm{Kg}^{-1}$.

Tabela 2 - Concentração de macronutrientes ( $\mathrm{g} \mathrm{Kg}^{-}$ ${ }^{1}$ de matéria seca) na parte aérea das plantas de alface, cv. Verônica, em função das diferentes condutividades elétricas da solução nutritiva.

\begin{tabular}{ccccccc}
\hline $\mathbf{C E}$ & \multicolumn{7}{c}{ Nutrientes $\left(\mathbf{g ~ K g}^{-1}\right)$} \\
\cline { 2 - 7 }$(\mathbf{m S ~ c m}$ \\
& $\mathbf{1})$ & $\mathbf{N}$ & $\mathbf{K}$ & $\mathbf{C a}$ & $\mathbf{M g}$ & $\mathbf{S}$ \\
\hline $\mathbf{1 , 0}$ & $38,18 \mathrm{~b}^{(*)}$ & $7,42 \mathrm{a}$ & $73,33 \mathrm{~b}$ & $21,30 \mathrm{ab}$ & $6,30 \mathrm{ab}$ & $2,19 \mathrm{c}$ \\
$\mathbf{1 , 5}$ & $42,88 \mathrm{a}$ & $8,00 \mathrm{a}$ & $76,67 \mathrm{~b}$ & $25,37 \mathrm{a}$ & $6,32 \mathrm{a}$ & $2,68 \mathrm{~b}$ \\
$\mathbf{2 , 0}$ & $42,29 \mathrm{a}$ & $8,12 \mathrm{a}$ & $78,33 \mathrm{~b}$ & $21,20 \mathrm{ab}$ & $6,87 \mathrm{a}$ & $2,81 \mathrm{~b}$ \\
$\mathbf{3 , 0}$ & $44,52 \mathrm{a}$ & $7,09 \mathrm{a}$ & $86,67 \mathrm{a}$ & $20,22 \mathrm{~b}$ & $5,40 \mathrm{~b}$ & $3,33 \mathrm{a}$ \\
\hline
\end{tabular}

* Médias seguidas de mesma letras na coluna não diferem entre si ao nível de 5\% de probabilidade, pelo Teste de Tukey.
Quando as plantas foram cultivadas em solução nutritiva com $\mathrm{CE}_{1}=1,0 \mathrm{mS} \mathrm{cm}{ }^{-1}$ obteve-se as menores concentrações de nitrogênio, potássio e enxofre, sendo que as concentrações de nitrogênio e enxofre diferiram significativamente dos demais tratamentos (Tabela 02). Huett (1994) verificou que plantas de alface (cv. Coolguard) cultivadas em baixa condutividade elétrica $\left(0,4 \mathrm{mS} \mathrm{cm}^{-1}\right)$, apresentaram deficiências de nitrogênio e potássio em folhas novas, sendo que as deficiências diminuíram com o aumento de condutividade elétrica da solução nutritiva. Huett (1994) também concluiu que o cultivo de alface nessa condutividade seria mais interessante, visto que as plantas apresentaram menor incidência de "tipburn". No presente experimento, não foi constatado incidência de "tipburn".

A concentração de potássio na planta aumentou conforme aumentou a condutividade elétrica da solução nutritiva, sendo que a concentração obtida na $\mathrm{CE}_{4}=3,0 \mathrm{mS} \mathrm{cm}{ }^{-1}$ diferiu significativamente dos demais tratamentos. Também nesse tratamento, as concentrações de cálcio e magnésio nas plantas foram as menores, podendo ser explicado pela inibição competitiva entre potássio, cálcio e magnésio (Tabela 2). Van Itallie (1938) verificou que quanto maior a concentração de um cátion em relação à concentração de potássio, maior tem sido a diminuição na absorção pelas plantas. De fato, Viets (1942) mostrou que quando a concentração relativa de cálcio em relação a potássio é baixa, o cálcio favorece a absorção de potássio pelas plantas, e somente quando o cálcio é incrementado, a absorção de potássio diminui. Pierre e Bower (1943) após revisar vários trabalhos referentes ao antagonismo entre íons, verificaram que na maioria das vezes o potássio possui uma maior habilidade competitiva que os outros cátions, e o decréscimo no teor de potássio devido a alta concentração de outros cátions não é tão pronunciado como é o efeito de potássio sobre a absorção de cálcio ou magnésio.

Com relação a extração de nutrientes pelas plantas de alface, somente o enxofre apresentou diferença significativa dos demais tratamentos e essa extração 
aumentou de acordo com o aumento da condutividade elétrica da solução nutritiva, sendo o maior valor obtido no tratamento $\mathrm{CE}_{4}=3,0 \mathrm{mS} \mathrm{cm}^{-1}$. A extração dos demais nutrientes não apresentou diferença significativa entre os tratamentos analisados e da mesma forma que os resultados de matéria fresca e seca, a extração de nutrientes aumentou conforme o aumento da condutividade elétrica até $\mathrm{o}$ tratamento $\mathrm{CE}_{3}=2,0 \mathrm{mS}$ $\mathrm{cm}^{-1}$, com exceção do cálcio (Tabela 3).

Tabela 3 - Extração de nutrientes $\left(\mathrm{g} \mathrm{pl}^{-1}\right)$ pelas plantas de alface, cv. Verônica, em função das diferentes condutividades da solução nutritiva.

\begin{tabular}{|c|c|c|c|c|c|c|}
\hline \multirow{2}{*}{$\begin{array}{c}\mathrm{CE} \\
\left(\mathrm{mS} \mathrm{cm} \mathrm{cm}^{-1}\right)\end{array}$} & \multicolumn{6}{|c|}{ Nutrientes (g planta $\left.{ }^{-1}\right)$} \\
\hline & $\mathbf{N}$ & $\mathbf{P}$ & $\mathbf{K}$ & $\mathbf{C a}$ & Mg & $\mathbf{S}$ \\
\hline 1,0 & $0,462 \mathrm{a}^{\left({ }^{*}\right)}$ & $0,091 \mathrm{a}$ & $0,898 \mathrm{a}$ & $0,257 \mathrm{a}$ & $0,076 \mathrm{a}$ & $0,027 \mathrm{~b}$ \\
\hline 1,5 & $0,583 \mathrm{a}$ & $0,108 \mathrm{a}$ & $1,043 \mathrm{a}$ & $0,345 \mathrm{a}$ & $0,086 \mathrm{a}$ & $0,036 \mathrm{ab}$ \\
\hline 2,0 & $0,623 \mathrm{a}$ & $0,119 \mathrm{a}$ & $1,156 \mathrm{a}$ & $0,300 \mathrm{a}$ & $0,096 \mathrm{a}$ & $0,041 \mathrm{ab}$ \\
\hline $\mathbf{3 , 0}$ & $0,571 \mathrm{a}$ & $0,091 \mathrm{a}$ & $1,116 \mathrm{a}$ & $0,260 \mathrm{a}$ & $0,069 \mathrm{a}$ & $0,042 \mathrm{a}$ \\
\hline
\end{tabular}

* Médias seguidas de mesma letras na coluna não diferem entre si ao nível de $5 \%$ de probabilidade, pelo Teste de Tukey.

Koefender (1996) verificou em alface, cv. Verônica, a extração de $\mathrm{N}, \mathrm{P}, \mathrm{K}, \mathrm{Ca}, \mathrm{Mg}$ e $\mathrm{S}$ entre 0,308 e 0,$433 ; 0,064$ e 0,$095 ; 0,600$ e 0,$671 ; 0,084$ e 0,$098 ; 0,020$ e 0,$026 ; 0,019$ e $0,024 \mathrm{~g} \mathrm{pl}^{-1}$, respectivamente. Garcia (1982) em cultivo à campo, obteve para as cultivares Brasil 48 e Clause's Aurélia: 0,470 e $0,410 \mathrm{~g} \mathrm{pl}^{-1}$ de nitrogênio, 0,100 e $0,100 \mathrm{~g} \mathrm{pl}^{-1}$ de fósforo, 1,017 e $0,759 \mathrm{~g} \mathrm{pl}^{-1}$ de potássio, 0,161 e $0,200 \mathrm{~g}$ $\mathrm{pl}^{-1}$ de cálcio, 0,047 e $0,052 \mathrm{~g} \mathrm{pl}^{-1}$ de magnésio e 0,021 e $0,021 \mathrm{~g} \mathrm{pl}^{-1}$ de enxofre, respectivamente. No experimento realizado por Fernandes et al. (1971) obtiveram: $0,387 \mathrm{~g} \mathrm{de} \mathrm{pl}^{-1}, 0,073 \mathrm{~g}$ de $\mathrm{P} \mathrm{pl}^{-1}, 0,848 \mathrm{~g}$ de $\mathrm{K}$ $\mathrm{pl}^{-1}, 0,222 \mathrm{~g}$ de $\mathrm{Ca} \mathrm{pl}^{-1}, 0,053 \mathrm{~g}$ de $\mathrm{Mg} \mathrm{pl}^{-1}$ e $0,050 \mathrm{~g}$ de $\mathrm{S} \mathrm{pl}^{-1}$, resultados semelhante ao deste experimento.

O teor de nitrato avaliado nas plantas de alface aumentou de acordo com o aumento das condutividades elétricas, e o valor obtido no tratamento $\mathrm{CE}_{4}=3,0 \mathrm{mS} \mathrm{cm}^{-1}$ foi estatisticamente superior aos demais tratamentos (Tabela 4). O monitoramento do teor de nitrato nos alimentos é muito importante devido ao nitrato e nitrito serem substâncias tóxicas ao homem. O nitrato forma ferremoglobina causadora da metanemia, e o nitrito permite a formação de nitrosaminas, produto cancerígeno e mutagênico. A Organização Mundial da Saúde estabeleceu o limite de 3,65 mg dia ${ }^{-1}$ por $\mathrm{Kg}$ de peso vivo para ingestão diária admissível de nitrato sem risco para a saúde (ESCOIN-PEÑA et al., 1998). Santamaria (1997) constatou que entre os produtos alimentares consumidos pelo homem, os vegetais representam entre 72 a $94 \%$ da ingestão diária de nitrato.

Tabela 4 - Teor de nitrato na parte aérea das plantas da alface, cv. Verônica, em função das diferentes condutividades elétricas da solução nutritiva.

\begin{tabular}{|c|c|}
\hline $\begin{array}{c}\mathrm{CE} \\
\left.(\mathrm{mS} \mathrm{cm})^{-1}\right)\end{array}$ & $\begin{array}{c}\text { Teor de Nitrato } \\
\left(\mathrm{mg} \mathrm{Kg}^{-1} \text { de peso fresco) }\right.\end{array}$ \\
\hline 1,0 & $442.10 \mathrm{~b}^{(*)}$ \\
\hline 1,5 & $524.75 \mathrm{~b}$ \\
\hline 2,0 & $589.85 \mathrm{~b}$ \\
\hline 3,0 & $763.74 \mathrm{a}$ \\
\hline
\end{tabular}

* Médias seguidas de mesma letras não diferem entre si ao nível de de $5 \%$ de probabilidade pelo Teste de Tukey.

Através do regulamento europeu no 194/97, o limite máximo de nitrato permitido em alface é de $4.500 \mathrm{mg} \mathrm{Kg}^{-1}$ de peso fresco quando o cultivo ocorre no inverno e $2.500 \mathrm{mg} \mathrm{Kg}^{-1}$ de peso fresco no verão (ESCOÍN-PEÑA et al.,1998). Petersen e Stoltze (1999) verificaram claramente um maior teor de nitrato quando o cultivo ocorreu no inverno e menor durante o verão.

Comparando-se o limite de $4.500 \mathrm{mg} \mathrm{Kg}^{-1}$ de peso fresco (o experimento realizou-se no inverno), com máximo teor de nitrato $\left(763,74 \mathrm{mg} \mathrm{Kg}^{-1}\right.$ de peso fresco) obtido neste experimento, observa-se que o teor de nitrato estava dentro do padrão estabelecido pela Europa. Lyons et al. (1994) obtiveram em alface hidropônica, teores de nitrato de $465 \mathrm{mg} \mathrm{Kg}^{-1}$ de peso fresco. Já em estudos realizados por Beninni et al. (2002) o teor médio de nitrato encontrado em alface 
hidropônica foi de $1.588 \mathrm{mg} \mathrm{Kg}^{-1}$ de peso fresco, com máximo de $2.568 \mathrm{mg} \mathrm{Kg}^{-1}$ de peso fresco e mínimo de $471 \mathrm{mg} \mathrm{Kg}^{-1}$ de peso fresco, e no cultivo convencional o teor médio de nitrato foi de $939 \mathrm{mg} \mathrm{Kg}^{-1} \mathrm{de}$ peso fresco, com máximo de $1.910 \mathrm{mg} \mathrm{Kg}^{-1}$ de peso fresco e mínimo de $26 \mathrm{mg} \mathrm{Kg}^{-1}$ de peso fresco.

Esses resultados demonstram que é possível produzir alface hidropônica com baixo teor de nitrato, desde que seja utilizada solução nutritiva com quantidades equilibradas de nutrientes. Para elaboração da solução nutritiva utilizada nesse experimento, houve atenção especial ao molibdênio, devido à sua disponibilidade influenciar a atividade da reductase do nitrato, enzima responsável pela redução do nitrato em amônia no interior da planta (MARSCHNER, 1986).

\section{Conclusões}

- a $\mathrm{CE}=1 \mathrm{mS} \mathrm{cm}^{-1}$ proporcionou alfaces de qualidade e boa produtividade;

- o cultivo de alface hidropônica com solução nutritiva equilibrada, resultou em produtos com baixo teor de nitrato;

- o teor de nitrato avaliado nas plantas de alface (média de 580,11 $\mathrm{mg} \mathrm{Kg}^{-1}$ de peso fresco) foi baixo, estando abaixo do limite máximo permitido pelo regulamento europeu para cultivo de inverno (4.500 $\mathrm{mg} \mathrm{Kg}^{-1}$ de peso fresco).

\section{Referências}

BENINNI, E. R .Y et al. Teor de nitrato em alface cultivada em sistemas hidropônico e convencional. Horticultura Brasileira, Brasília, v.20, n.2, p.183-186, jun. 2002.

BLISKA JUNIOR, A.; HONÓRIO, S. L. Cartilha Tecnológica de Hidroponia. Campinas: Unicamp, 1996.

CATALDO, D. A. et al. Rapid colorimetric determination of nitrate in plant tissue by nitration of salicylic acid. Communications Soil Science and Plant Analysis, Monticello, v.6, n.1, p.71-80, 1975.
COSTA, P. C. et al. Condutividade elétrica da solução nutritiva e produção de alface em hidroponia. Scientia Agrícola, Piracicaba, v.58, n.3, p.595-597, jul./set. 2001.

ESCOÍN- PEÑA, M.C. et al. Contenido de nitratos en lechugas y espinacas frescas. Alimentaria, Madrid, n.298, p.37-41, 1998.

FERNANDES, P. D.; OLIVEIRA, G. D.; HAAG, H. P. Nutrição mineral de hortaliças. Absorção de nutrientes pela cultura da alface. $O$ Solo, Piracicaba, ano 63, v.2, p.7-10, 1971.

GARCIA, L. L. C. Absorção de macro e micronutrientes e sintomas de carência de macronutrientes em alface (Lactuca sativa L.), cv. Brasil 48 e Clause's Aurélia. 1982. 78f. Tese (Mestrado em Solos e Nutrição de Plantas) Escola Superior de Agricultura Luiz de Queiroz, Universidade de São Paulo, Piracicaba.

GRAVES, C. J. The nutrient film technique. In: JANICK, J. (Ed). Horticultural reviews. Westport: AVI, 1983. p.1-44.

HOAGLAND, D. R; ARNON, D. I. The water culture method for growing plants without soil. Berkeley:Univ. of Calif. Agric. Exp. Station, 1950. (Circular 347).

HUETT, D. O. Growth, nutrient uptake and tipburn severity of hidroponic lettuce in response to electrical conductivity and $\mathrm{K}: \mathrm{Ca}$ ratio in solution. Australian Journal of Agricultural Research, Collingwood, v.45, p.251-267, 1994.

KOEFENDER, V. N. Crescimento e absorção de nutrientes pela alface cultivada em fluxo laminar de solução. 1996. 85f. Tese (Mestrado em Solos e Nutrição de Plantas) - Escola Superior de Agricultura Luiz de Queiroz, Universidade de São Paulo, Piracicaba.

LYONS, D .J. et al. Nitrate and nitrite in fresh vegetables from Queensland. Journal of the Science of Food and Agriculture, Chichester, v.64, n.3, p.279-281, 1994.

MARSCHNER, H. Mineral nutrition of higher plants. London: Academy Press, 1986.

MARTINEZ, H. E. P. Formulação de soluções nutritivas para cultivos hidropônicos comerciais. Jaboticabal: Funep, 1997.

PETERSEN, A.; STOLTZE, S. Nitrate and nitrite in vegetables on the Danish market: content and intake. Food Additives and Contaminants, London, v.16, n.7, p.291299, 1999.

PIERRE, M. H.; BROWER, C. A. Potassium absorption by plants as affected by cationic relationships. Soil Science, Baltimore, v.55, p.23-36, 1943. 
RAIJ, B. Van. et al. (Eds.). Recomendações de adubação e calagem para o estado de São Paulo (Boletim 100). 2.ed. Campinas: Instituto Agronômico \& Fundação IAC, 1996.

SANTAMARIA, P. Contributo degli ortaggi all' assunzione giornaliera di nitrato - nitrito e nitrosamina. IndustrieAlimentari, Pinerolo v.36, n.364, p.1329-1334, 1997.

STAFF, H. Hidroponia. 2 ed. Cuiabá: SEBRAE/MT, 1998.

VAN ITALLIE, T. B. Cation equilibria in plants in relation to the soil. Soil Science, Baltimore, v.46, p.175186, 1938.
VERDONCK, O.; VLEESCHAUWER, D.; BOODT, M. The influence of the substrate to plant growth. Acta Horticulturae, Wageningen, v.126, p.251-258, 1981.

VIETS JUNIOR, F.G. Effects of calcium and other divalent ions on the accumulation of monovalent ions by barley root cells. Science, Washington, v.95, p.486-487, 1942. 
